\title{
What Makes a 'Successful' Psychopath? Longitudinal Trajectories of Offenders' Antisocial Behavior and Impulse Control as a Function of Psychopathy
}

\author{
Emily N. Lasko*, David S. Chester \\ Department of Psychology, Virginia Commonwealth University, USA \\ in press at Personality Disorders: Theory, Research, and Treatment
}

${ }^{*}$ Correspondence regarding this article should be addressed to:

Emily N. Lasko

916 W. Franklin St.

Virginia Commonwealth University

Richmond, VA 23284, USA

laskoen@vcu.edu 


\begin{abstract}
Psychopathy is a considerable risk factor for violent behavior. However, many psychopathic individuals refrain from antisocial and criminal acts. The mechanisms underlying the formation of this 'successful' phenotype are uncertain. We tested a compensatory model of 'successful' psychopathy, which posits that relatively 'successful' psychopathic individuals develop greater conscientious traits that serve to inhibit their heightened antisocial impulses. To test this model, we examined the sevenyear longitudinal Research on Pathways to Desistance study of 1,354 adjudicated adolescents. Higher initial psychopathy was associated with steeper increases in general inhibitory control and the inhibition of aggression over time. This effect was magnified among 'successful' offenders (i.e., those who reoffended less). These findings support our compensatory model, suggesting that psychopathic individuals who develop greater self-regulatory control over their antisocial impulses become relatively more 'successful' than their less regulated counterparts. Moreover, our results speak to the importance of the Five-Factor Model for understanding psychopathy and the crucial role of conscientiousness in the form that psychopathic individuals take.
\end{abstract}

Keywords: psychopathy, conscientiousness, antisocial behavior, criminal offending, successful psychopathy 


\section{Introduction}

Psychopathy is a personality construct that is characterized by remorselessness, blunted empathy, and manipulative tendencies (Hare, 1999, 2003). Far from being unique to violent criminal offenders, psychopathy exists on a spectrum across the human population (Lilienfeld, Watts, \& Smith, 2015; Miller \& Lynam, 2003; Patton, Smith, \& Lilienfeld, 2017). In contrast to 'unsuccessful' psychopaths who are incarcerated due to their antisocial proclivities, a large proportion of psychopathic individuals manage to lead non-incarcerated lives (Hare, 1999). This unique subgroup of individuals is known in modern nomenclature as 'successful' psychopaths (Lilienfeld, Watts, \& Smith, 2015). The 'successful' psychopathic individual dons a "mask of sanity" (Cleckley, 1955, pp. 190 - 191) - adapting to societal norms and living a conventional life. The concept of 'successful' psychopathy has long been a matter of contention due in large part to the dearth of empirical research on the subject as well as the definitional ambiguities (Lilienfeld, Watts, \& Smith, 2015). Further, the psychological processes that allow 'successful' psychopathic individuals to avoid succumbing to their antisocial impulses remains imperfectly understood. In the present study, we tested a compensatory model of 'successful' psychopathy - in which 'successful' psychopathic individuals are those who develop stronger self-regulatory skills over the course of their life.

\section{Characteristics of 'Successful' and 'Unsuccessful' Psychopaths}

Psychopathy is a multifaceted construct with various manifestations depending on the specific phenotypic expression of traits (Bronchain, Raynal, \& Chabrol, 2019; Hare, 1993). Prominent models of psychopathy attempt to articulate the various facets 
that define psychopathy (e.g., the Triarchic Model of Psychopathy; Patrick \& Drislane, 2015). Yet the specific parameters that define a psychopathic individual's 'success' remain under robust debate (e.g., personal achievements versus contributions to society; Lilienfeld, Watts, \& Smith, 2015). Some scholars contended that the concept of 'successful' psychopathy was oxymoronic because of the pathological nature of psychopathy itself (Kiehl \& Lushing, 2014). Conversely, others argued that 'successful' psychopathy reflects an expression of certain psychopathic traits that contribute to personal achievements in many life domains (e.g., occupational success) while simultaneously subverting adverse outcomes (e.g., incarceration; Benning, Venables, \& Hall, 2018; Hall \& Benning, 2006). We side with these latter arguments, suggesting that 'successful' and 'unsuccessful' forms of psychopathy different life outcomes (e.g., nonincarcerated membership in society versus incarceration for criminal offending) and reflect different combinations of the psychopathic traits.

A growing body of evidence supports the view that 'successful' psychopathic individuals possess different psychological traits than their less 'successful' counterparts, and that these traits have an integral impact on their 'success'. For instance, psychopathic fearlessness (also referred to as boldness) is often elevated among individuals in elite (e.g., lawyers, business executives) and risky professions (e.g., first-responders; Gao \& Raine, 2010; Lilienfeld, Watts, \& Smith, 2015; Patton, Smith, \& Lilienfeld, 2017). Such boldness can be an adaptive trait that is elevated among 'successful' psychopathic individuals, as with other traits such as grandiosity, interpersonal manipulation, and social poise (Lilienfeld et al., 2016; Patton, Smith, \& Lilienfeld, 2017). Additionally, 'successful' psychopaths exhibit enhanced executive 
functioning during various laboratory measures of these cognitive abilities (Gao \& Raine, 2010). Conversely, impulsive behavior is more prevalent in 'unsuccessful' psychopathic individuals, due (in large part) to their impaired executive function and self-regulatory control (Gregory et al., 2012; Lykken, 1995; Patton, Smith, \& Lilienfeld, 2017). From these findings, it is clear that 'successful' and 'unsuccessful' psychopaths differ along many psychopathic traits, yet the traits that chiefly predict which group that psychopaths will fall into remains unknown.

\section{The Role of Conscientiousness in Promoting 'Successful' Psychopathy}

There is good reason to expect that the most robust trait dimension underlying the development of 'successful' psychopathy is conscientiousness. Conscientiousness refers to a collection of psychological traits that are organized around the themes of planning for the future, being goal-directed, following rules, being self-disciplined, and delaying gratification (Roberts, Jackson, Fayard, Edmonds, \& Meints, 2009). In support of conscientiousness' crucial role in 'successful' psychopathy, psychopathy experts rated conscientiousness as the trait dimension that was most likely to differentiate whether psychopathic individuals become 'successful' or 'unsuccessful' (Clower \& Bothwell, 2002; Mullins-Sweatt, Glover, Derefinko, Miller, \& Widiger, 2010; Ozer \& Benet-Martinez, 2006). Further, the assertion that high conscientious may lie at the core of 'successful' variants of psychopathy is in line with Hare's (1993) original descriptions and conceptualization of the construct (Lynam \& Widiger, 2007).

A core feature of conscientiousness is inhibitory control, through which individuals are able to stifle their pre-potent impulses (Roberts, Bogg, Walton, Chernyshenko, \& Stark, 2004). This ability can assist in the inhibition of antisocial 
impulses that are prevalent among individuals high in psychopathy (e.g., stealing a stranger's vulnerable smartphone; Konicar et al., 2015; Nomura, 2011). Although inhibitory control is a crucial aspect of the psychopathic personality, high levels of it are not redundant with 'successful' psychopathy per se. Conversely, poor impulse control is not redundant with 'unsuccessful' psychopathy. Instead, poor inhibitory control is only one characteristic of many that describe these forms of psychopathy (Patrick \& Drislane, 2015; Skeem, Poythress, Edens, Lilienfeld, \& Cale, 2003). Indeed, psychopathy is also most centrally characterized by antagonistic traits such as callousness, interpersonal manipulation, and grandiosity - traits that are integral to the construct (Jones \& Figueredo, 2013; Marcus, Preszler, \& Zeigler-Hill, 2018; MullinsSweat et al., 2010; Thomson, 2019; Vize, Collison, Miller, \& Lynam, 2019). Further, manipulativeness tends to account for the most variance in the overlap between psychopathy and the other members of the Dark Triad (Vize, Collison, Miller, \& Lynam, 2019). The antisocial behavior of psychopathic individuals may simply reflect downstream effects of these core psychopathy traits (Thomson, 2019). Therefore, it is the unique combination of heightened antagonism (e.g., grandiosity, manipulativeness) with either lower or higher impulse control that characterizes the 'successful' versus 'unsuccessful' psychopathy phenotypes.

\section{The Compensatory Model of 'Successful' Psychopathy}

Given the crucial role of impulse control in 'successful' psychopathy, we proposed the compensatory model of 'successful' psychopathy (Lasko, Chester, Martelli, West, \& DeWall, 2019). This model posits that 'successful' psychopathic individuals become 'successful' by developing greater inhibitory control to compensate 
for their heightened antisocial impulses. Further, the model suggests that this compensatory, inhibitory mechanism should be specific to facets of psychopathy that have been are more prevalent in the broad swath of 'successful' individuals in general grandiosity and interpersonal manipulation (Lilienfeld, Watts, \& Smith, 2015; Patton, Smith, \& Lilienfed, 2017).

\section{The Present Research}

The compensatory model of 'successful' psychopathy remains a preliminary theoretical framework. Towards providing a stronger empirical foundation for this model, we obtained data from a large, longitudinal study of adjudicated adolescent offenders (i.e., the Research on Pathways to Desistance database; Mulvey, 2017). Although these participants are not objectively 'successful', this was an ideal sample to test our hypotheses for two main reasons. First, adolescents are in a prime developmental phase for the improvement of impulse control. Allowing us the longitudinal variability we would need to test our compensatory model. Second, offenders are prone to antisocial acts, by definition, and their rates of recidivism provided a real-world index of 'successful' versus 'unsuccessful' psychopathy phenotypes. Because offenders are ultimately an 'unsuccessful' population, we use the 'successful' and 'unsuccessful' in purely relative terms (i.e., reoffending fewer times than other offenders). Bearing this in mind, we predicted that greater grandiose-manipulative psychopathic traits (but not impulsive-irresponsible traits), at the outset of the study, would be linked to steeper increases in impulse control over time, particularly among 'successful' participants (i.e., individuals who reoffended less). As noted previously, our compensatory model suggests that a 'successful' life trajectory would rely more on the interpersonal aspects 
of the psychopathic personality (i.e., grandiose-manipulative traits) rather than the affective components (i.e., callous-unemotionality). Thus, we made no predictions regarding the callous-unemotional dimension. We also preregistered analyses that would have employed the Psychopathy Checklist-Youth Version (PCL-YV), though we were ultimately unable to do so because only baseline data were available. We also predicted that conscientiousness would mediate the link between grandiosemanipulative psychopathic traits and criminal reoffending over time. However, we were unable to test this latter hypothesis because the conscientiousness variable was only available at one time point. The preregistration plan for our predictions and analyses are publicly available: https://osf.io/2xtu9/. The data files are publicly available: https://doi.org/10.3886/ICPSR36800.v4.

\section{Method}

\section{Participants}

The Research on Pathways to Desistence study (Mulvey, 2017) was a multi-site longitudinal investigation that examined adolescent criminal offending from 2003 to 2010. Participants were male and female adolescent offenders $(N=1354 ; 86.5 \%$ male; age: $M=18.05, S D=1.16$ ) who were recruited from court systems in Phoenix, Arizona $(N=654)$ and Philadelphia, Pennsylvania $(N=700)$. Initial enrollment occurred from November 2000 to January 2003. Assessments occurred every six months for seven years (2003 until 2010), resulting in 14 potential timepoints per participant. Participants were included in the study if they were $14-17$ years old at the time of an offense and that this offense was a felony or serious misdemeanor (e.g., sexual assault, weapons offenses). We only included data from times 1 through 10 in the present analyses 
because the psychopathy and impulse control variables were not available at times 11 14.

Measures

Youth Psychopathic Traits Inventory (YPI). The YPI is a self-report measure of psychopathic traits developed for youth populations under the age of 18 (Andershed, Kerr, Stattin \& Levander, 2002). The 50 -item measure rated the extent to which various statements applied to themselves along a 4-point Likert scale from 1 (does not apply at all) to 4 (applies very well). Three separate trait subscales were computed: grandiosemanipulative (sample item: "I have the ability to con people by using my charm and smile"), callous-unemotional (sample item: "I seldom regret things I do, even if other people feel that they are wrong"), and impulsive-irresponsible (sample item: "I get bored quickly when there is too little change").

Weinberger Adjustment Inventory (WAI). The WAI is a 23-item measure of social and emotional adjustment, particularly regarding self-regulatory ability (Weinberger \& Schwartz, 1990). The two subscales of central interest to the present analyses were the eight item impulse control subscale (e.g., "I say the first thing that comes into my mind without thinking enough about it") and the 7 item suppression of aggression subscale (e.g., "people who get me angry better watch out") subscales. Items are rated along a 1 (False) to 5 (True) scale.

Self-Reported Offending (SRO) questionnaire. The 24-item SRO questionnaire (Huizinga, Esbensen, \& Weihar, 1991) assessed offense history at the baseline interview and every six months in the subsequent ten data collection periods. The SRO asked about the individual's involvement in various types of crime within the 
last recall period (i.e., the preceding six months). Items on the SRO are divided into two categories of offending: aggressive (e.g., "have you been in a fight?") and income (e.g., "have you used checks or credit cards illegally?"). The aggressive offense and income offense subscales were combined into a total offenses variable, which reflected a frequency count of offenses over the relevant time period. Given that 'successful' individuals are less likely to engage in explicit, aggressive forms of criminal behavior (Lilienfeld, Watts, \& Smith, 2015), we employed the total offenses score in order to capture the largest amount of reoffending.

\section{Statistical Analyses}

Latent growth curve modeling. In order to test the hypothesis that grandiosemanipulative traits would be associated with greater increases in self-regulation over time, particularly among 'successful' participants (i.e., individuals who did not reoffend), we utilized latent growth curve modeling (LGCM) using AMOS (Version 22.0) for SPSS (Version 24.0). LGCM is a method of modeling longitudinal data that permits the assessment of both intra-individual and inter-individual change over time (Preacher, Wichman, Briggs, \& MacCallum, 2008). Our main interest in the present study was the latent association between the intercept (i.e., initial scores) of grandiose-manipulative psychopathic traits and the slopes (i.e., growth rates) of impulse control and suppression of aggression. This correlation reflected the extent to which relatively more psychopathic offenders exhibited accelerated acquisition of conscientiousness over time - the core tenet of our compensatory model of 'successful' psychopathy.

We fit a series of parallel process LGCMs in order to simultaneously examine the trajectories of two variables over time. In the first model, the grandiose-manipulative 
subscale of the YPI and the impulse control subscale of the WAI at all ten time points (approximately five years), served as the manifest indicators of the latent intercept and slope variables of psychopathy and self-regulation, respectively. In the second parallel process LGCM, we simply substituted the suppression of aggression subscale of the WAl for the impulse control subscale from the first model. Using these two selfregulatory constructs was ideal because they directly map on to the core mechanism of interest, self-regulatory constraint of antisocial impulses (Weinberger \& Schwartz, 1990).

\section{Results}

\section{Descriptive Statistics and Correlations}

The descriptive statistics for each time point of data collection used in the present study appear in Supplemental Table 1. Bivariate correlations among all variables appears in Supplemental Table 2. Due to the large number of variables and time points used in the present analyses, only correlations from time points 4 and 10 are reported (as these were two of the time points with the largest sample sizes).

\section{Latent Growth Curve Models}

Trajectories of impulse control. The first parallel process LGCM, which examined grandiose-manipulative traits and impulse control, exhibited an adequate fit to the data, RMSEA $=.05(90 \% \mathrm{Cl}=0.05,0.06), C F I=.95$. The slope of grandiosemanipulative traits decreased over time, $\beta=-.06, S E=.003, p<.001$, whereas the slope of impulse control increased over time, $\beta=.06, S E=.005, p<.001$ (Figure 1). Replicating the well-established inverse association between psychopathy and impulse control (Gansler et al., 2011; Konicar et al., 2015), the intercept-intercept and slope- 
slope associations between these two variables were negative. Participants' initial grandiose-manipulative traits were associated with a steeper decline in grandiosemanipulative traits over time, whereas participants' initial impulse control was associated with a steeper incline in impulse control over time. Supporting our preregistered prediction, participants' initial levels of grandiose-manipulative traits were associated with a steeper increase of impulse control over time. The trajectories of these two variables were negatively associated, indicating that the development of better impulse control was associated with an even steeper decline in grandiosemanipulative traits over time.

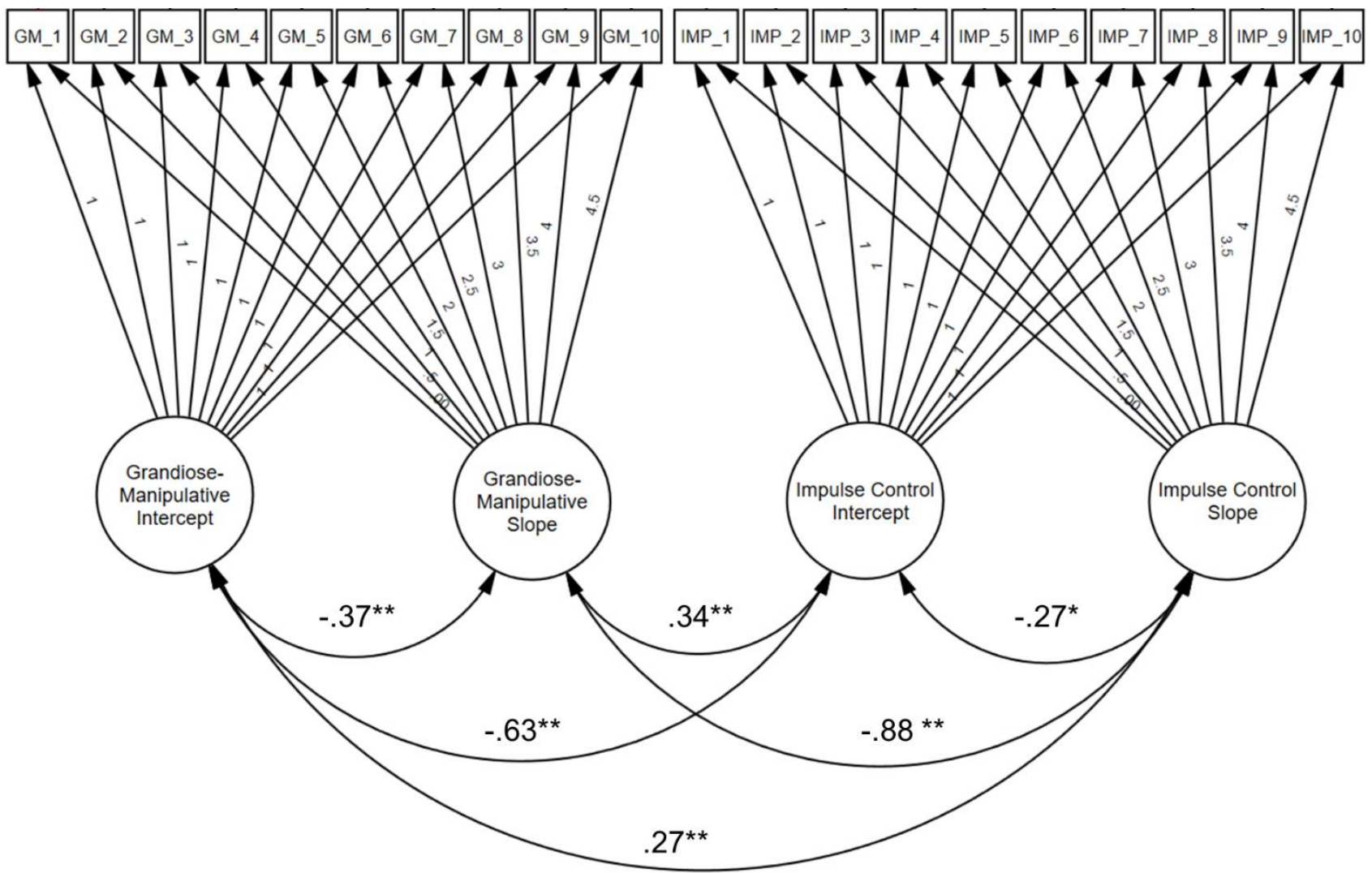

Figure 1. Parallel process latent growth curve model depicting the trajectories of change in grandiose-manipulative traits and impulse control across ten time points (five years). Values indicate standardized regression coefficients.

${ }^{* *} p<.001,{ }^{*} p=.011$ 
Moderation by 'successful' versus 'unsuccessful' status. In order to examine whether growth trajectories in grandiose-manipulative traits and impulse control differed between individuals who reoffended (i.e., 'unsuccessful' individuals) and those who were not (i.e., 'successful' individuals), we employed a group invariance design, which was not pre-registered. We focused these invariance analyses on time points $2-6$, as participants could not reoffend at the first time point and time points 7-10 had too few participants who had not reoffended (Supplemental Table 1). Participants were coded as follows: 1 = 'unsuccessful' (at least one offense across the five time points), $0=$ 'successful' (no offenses at any of the five time points).

This invariance LGCM provided adequate fit to the data, $R M S E A=.05(90 \% \mathrm{Cl}=$ $0.04,0.06), C F I=.97$. The means and the covariances were significantly different between 'successful' and 'unsuccessful' groups, $X^{2}(4)=87.54, p<.001$ and $X^{2}(14)=$ $108.10, p<.001$, respectively, indicating non-invariance. Consistent with our preregistered predictions, the positive correlation between the initial grandiosemanipulative traits and the slope of impulse control over time was nearly twice as large for 'successful' participants as compared to their 'unsuccessful' counterparts (Table 1). Table 1. Latent growth trajectories of 'Successful' and 'Unsuccessful' participants.

\begin{tabular}{lcccccc}
\hline \multirow{2}{*}{ Path } & \multicolumn{3}{c}{ 'Successful' $(N=230)$} & \multicolumn{3}{c}{ 'Unsuccessful' $(N=1030)$} \\
\cline { 2 - 7 } & $\beta$ & $\mathrm{B}(\mathrm{SE})$ & $p$ & $\beta$ & $\mathrm{B}(\mathrm{SE})$ & $p$ \\
\hline GM (I) <--> GM (S) & -.35 & $-0.03(.01)$ & .006 & -.38 & $-0.04(.01)$ & $<.001$ \\
IC (I) <--> IC (S) & -.22 & $-0.02(.01)$ & .167 & -.29 & $-0.03(.01)$ & $<.001$ \\
GM (I) <--> IC (I) & -.65 & $-0.33(.05)$ & $<.001$ & -.59 & $-0.32(.02)$ & $<.001$ \\
GM (S) <--> IC (S) & -1.15 & $-0.12(.00)$ & $<.001$ & -.85 & $-0.02(.00)$ & $<.001$ \\
GM (S) <--> IC (I) & .38 & $0.04(.01)$ & $<.001$ & .33 & $0.04(.01)$ & $<.001$ \\
GM (I) <--> IC (S) & .39 & $0.03(.01)$ & .009 & .26 & $0.03(.01)$ & $<.001$ \\
\hline
\end{tabular}


Note: $(I)=$ Intercept, $(S)=$ Slope, $G M=$ Grandiose - Manipulative psychopathy traits, IC $=$ Impulse Control.

Although there were fewer 'successful' individuals than 'unsuccessful' individuals, violating equality of variance assumptions, multivariate statistics are robust to such violations (Meyers, Gamst, \& Guarino, 2016; Voelkle, 2007; von Oertzen \& Brandmaier, 2013). Subsequent exploratory analyses that systematically altered the number of reoffenses that categorized individuals as 'successful' or 'unsuccessful' did not substantively affect our observed pattern of results (Supplemental Table 3). Additionally, using an alternative indicator of 'success' - educational enrollment (i.e., whether participants were enrolled in school during each recall period) - also replicated the larger positive correlations we observed among 'successful' individuals (i.e., those who were enrolled in school longer) compared to 'unsuccessful' individuals (Supplemental Table 4). Furthermore, when the same invariance model was fit with impulsiveirresponsible traits, both 'successful' and 'unsuccessful' participants showed a negative correlation between the initial impulsive-irresponsible traits and the slope of impulse control over time (Supplemental Table 7). 
Trajectories of suppression of aggression. The second parallel process

LGCM that examined the trajectories of change in grandiose-manipulative traits and suppression of aggression exhibited an adequate fit to the data, RMSEA $=.06(90 \% \mathrm{Cl}$ $=0.05,0.06), C F I=.94$. Paralleling the results of the previous LGCM on domaingeneral impulse control, the slope of grandiose-manipulative traits decreased over time, $\beta=-.06, S E=.003, p<.001$, whereas the slope of suppression of aggression increased over time, $\beta=.08, S E=.006, p<.001$ (Figure 2).

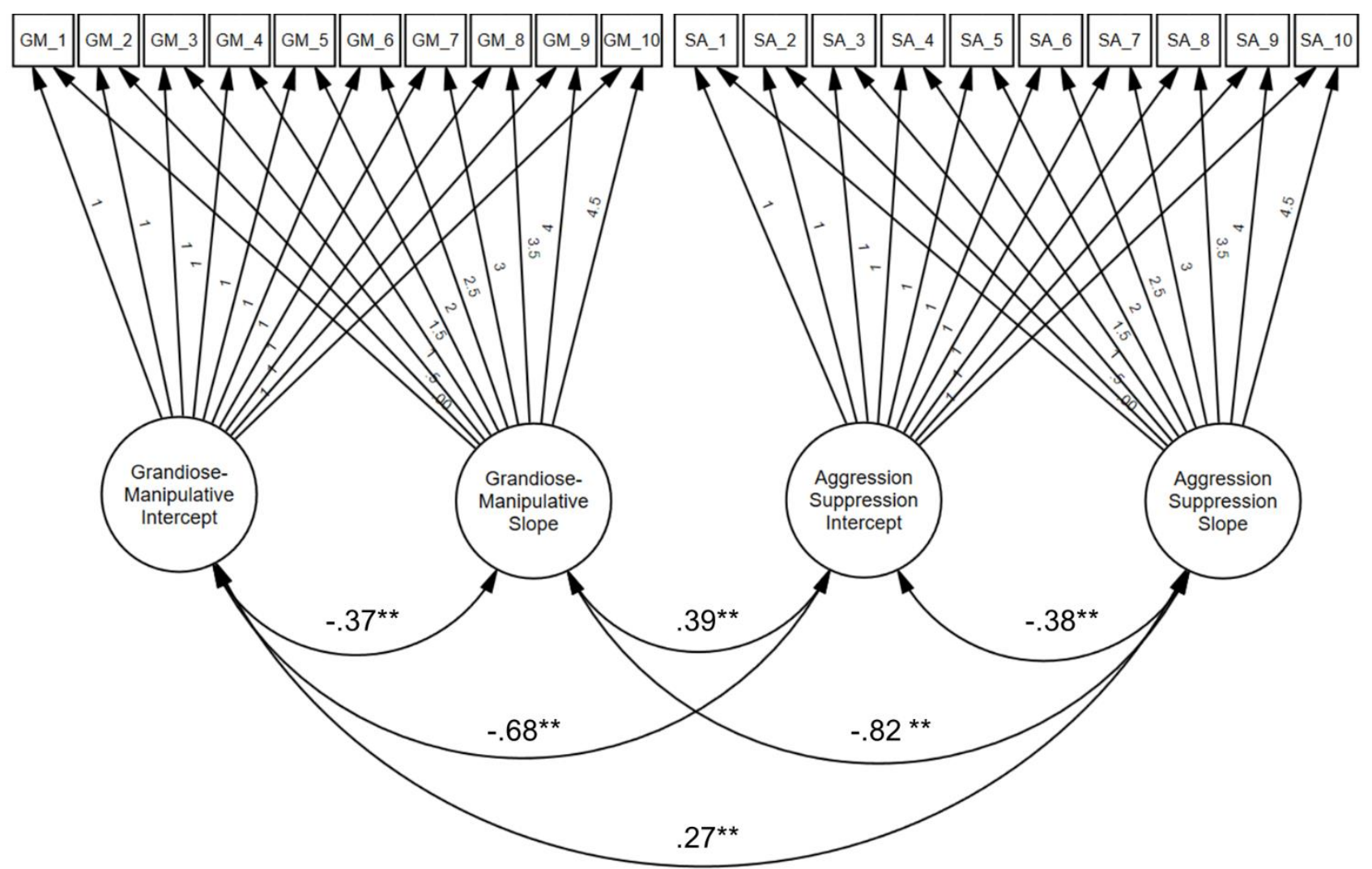

Figure 2. Parallel process latent growth curve model depicting the trajectories of change in suppression of aggression and grandiose-manipulative traits across ten time points (five years). Values indicate standardized regression coefficients. GM = GrandioseManipulative, $S A=$ Suppression of Aggression . 
The intercept-intercept and slope-slope associations between grandiosemanipulative traits and suppression of aggression were negative. Participants' initial grandiose-manipulative traits were associated with a steeper decline in grandiosemanipulative traits over time. Likewise, participants' initial suppression of aggression was associated with a steeper decline in suppression of aggression over time. The intercepts and slopes between grandiose-manipulative traits and suppression of aggression were negatively associated. Supporting our preregistered prediction, participants' initial levels of grandiose-manipulative traits were associated with a steeper increase in suppression of aggression over time. The slopes of these two variables were negatively associated, indicating that the development of better suppression of aggression ability is associated with an even steeper decline in grandiose-manipulative traits over time.

\section{Comparing 'Successful' and 'Unsuccessful' Groups}

We again employed a group invariance design that was not pre-registered. An invariance LGCM that focused on the suppression of aggression instead of domaingeneral impulse control exhibited adequate fit to the data, $R M S E A=.04,(90 \% \mathrm{Cl}=$ $0.04,0.05), C F I=.94$. Both the means and the covariances were significantly different between 'successful' and 'unsuccessful' groups, $X^{2}(4)=95.65, p<.001$ and $X^{2}(14)=$ $127.81, p<.001$, respectively, indicating non-invariance. Consistent with our predictions, the positive correlation between the initial grandiose-manipulative traits and the slope of suppression of aggression over time was over twice as large for 'successful' participants as compared to their 'unsuccessful' counterparts (Table 2). Systematically altering the number of re-offenses that categorized individuals as 
'successful' or 'unsuccessful' in our exploratory analyses again demonstrated that altering these criteria did not substantively affect our observed pattern of results (Supplemental Table 5). Additionally, using an alternative indicator of 'success' educational enrollment (i.e., whether participants were enrolled in school during each recall period) - also replicated the larger positive correlations we observed among 'successful' individuals (i.e., those who were enrolled in school longer) compared to 'unsuccessful' individuals (Supplemental Table 6).

Furthermore, when the same invariance model was fit with impulsiveirresponsible traits, both 'successful' and 'unsuccessful' participants again showed a negative correlation between the initial impulsive-irresponsible traits and the slope of suppression of aggression over time (Supplemental Table 8).

Table 2. Latent growth trajectories of 'Successful' and 'Unsuccessful' participants.

\begin{tabular}{lcccccc}
\hline & \multicolumn{3}{c}{ 'Successful' $(N=230)$} & \multicolumn{3}{c}{ 'Unsuccessful' $(N=1030)$} \\
\hline \multicolumn{1}{c}{ Path } & $\beta$ & B (SE) & $p$ & $\beta$ & B (SE) & $p$ \\
\hline GM (I) <--> GM (S) & -.36 & $-0.03(.01)$ & .007 & -.37 & $-0.04(.01)$ & $<.001$ \\
SA (I) <--> SA (S) & -.40 & $-0.05(.02)$ & $<.001$ & -.37 & $-0.04(.01)$ & $<.001$ \\
GM (I) <--> SA (I) & -.69 & $-0.39(.06)$ & $<.001$ & -.64 & $-0.33(.02)$ & $<.001$ \\
GM (S) <--> SA (S) & -.91 & $-0.02(.00)$ & $<.001$ & -.81 & $-0.02(.00)$ & $<.001$ \\
GM (S) <--> SA (I) & .36 & $0.04(.01)$ & .002 & .41 & $0.05(.01)$ & $<.001$ \\
GM (I) <--> SA (S) & .41 & $0.04(.01)$ & $<.001$ & .24 & $0.03(.01)$ & $<.001$ \\
\hline
\end{tabular}

Note: $(I)=$ Intercept,$(S)=$ Slope, $G M=$ Grandiose - Manipulative psychopathy traits, $S A=$ Suppression of Aggression .

\section{Discussion}

In considering the possible trait dimensions that most prominently characterize the 'successful' psychopathy phenotype, experts have largely converged on the role of enhanced conscientiousness and impulse control (Mullins-Sweatt et al., 2010). In the 
present study, we empirically tested compensatory model of 'successful' psychopathy

— in which 'successful' psychopaths develop greater impulse control that compensates for and restrains their antisocial tendencies (Lasko, Chester, Martelli, West, \& DeWall, 2019).

\section{The Compensatory Model of 'Successful' Psychopathy}

Supporting the compensatory model, we observed that higher levels of initial grandiose-manipulative psychopathy traits among a sample of adolescent offenders were associated with steeper increases in both impulse control and suppression of aggression over a period of five years. These findings suggest that individuals high in grandiose-manipulative psychopathic traits showed greater acquisition of domaingeneral (i.e., inhibitory control) and domain-specific (i.e., suppression of aggression) forms of conscientiousness across adolescent development. This exacerbated development of conscientiousness-defining traits are likely able to compensate for the heightened antisocial tendencies of these psychopathic individuals, bringing them into a self-regulatory balance that enables them to function in society. These findings provide a more nuanced understanding of antisocial individuals' approach to self-regulation, which has been conventionally typified as simply disinhibited (e.g., Jonason \& Tost, 2010). Psychopathic individuals may exhibit overall patterns of impaired self-regulatory abilities when compared to their less psychopathic counterparts. However, 'successful' psychopathic individuals may more quickly develop such self-regulatory skills than their more prosocial peers, though ultimately falling short of them. These findings demonstrate the added utility of a longitudinal approach to studying psychopathy, as 
well as one that focuses on the psychological advantages (i.e., faster development of self-regulation) of psychopathic individuals, and not just deficits.

The Crucial Role of Conscientiousness and the Five-Factor Model

In line with our compensatory model and the judgements of psychopathy experts (Mullins-Sweatt et al., 2010), the link between psychopathy and a steeper trajectory of conscientious trait development was magnified among 'successful' offenders (i.e., those who did not reoffend). These findings show the importance of the Five-Factor Model to understanding the nuances of psychopathy and its various phenotypes (Lynam \& Miller, 2015; Lynam \& Widiger, 2007). Conscientiousness and impulse control are clearly crucial constructs to consider in this domain of antisocial personality. Though models of psychopathy that emphasize only the low side of conscientiousness may apply less accurately to more 'successful' and regulated forms of this construct.

Together, these results point to the consequential nature of the development of conscientious traits for psychopathic individuals, which may promote adaptive re-entry into society. Indeed, even 'unsuccessful' offenders in our sample exhibited associations between their grandiose-manipulative traits and greater impulse control (albeit to a substantially lesser degree).

\section{Specificity and Generalizability}

We found evidence for our compensatory model, as expected, for grandiosemanipulative traits but not for impulsive-irresponsible traits. The specificity of this finding to more regulated forms of psychopathic traits supports the secondary tenet of our compensatory model (Lasko, Chester, Martelli, West, \& DeWall, 2019). Individuals with higher levels of impulsive psychopathic traits may thus not benefit from the 
compensatory developmental mechanisms we provided evidence for here. Yet the trajectory-based differences between 'successful' and 'unsuccessful' groups did replicate when we used educational enrollment as the categorical indicator of 'success'. This suggests that our findings are likely to generalize across various forms of 'success', though the extent of this applicability remains to be fully estimated.

Our compensatory model is similar to the moderated expression (ME) Model of 'successful' psychopathy, which proposes that some psychopathic individuals possess certain protective factors that influence their adaptive development (Lilienfeld, Watts, \& Smith, 2015). Yet our compensatory model articulates a specific trait mechanism (i.e., the inhibitory control inherent to greater conscientiousness) that facilitates the psychopath's 'success'. In contrast, the ME Model casts a wider net, theorizing that multiple protective factors (e.g., enhanced executive function, information processing ability, positive parenting) each attenuate various aspects of the psychopathic personality (Lilienfeld, Watts, \& Smith, 2015).

\section{Limitations and Future Directions}

The present study was not without limitations. First, and foremost, our sample was a homogenous group of adjudicated adolescents so the overall 'success' of these individuals remains debatable. Accordingly, we do not assert that individuals in our study were objectively 'successful'. Rather, we used a relative definition of 'success' that relied on their level of reoffending and educational attainment compared to their peers. Nonetheless, future studies should test our compensatory model within more diverse and objectively successful populations. 
Second, these statistical analyses were correlational in nature. Future work may try to experimentally-manipulate impulse control abilities and examine their interaction with psychopathic traits' effect on antisocial behavior in order to establish causal effects. Third, impulse control has a general tendency to increase throughout adolescence into adulthood, while psychopathic traits generally decrease. Thus, we are unable to rule out the possibility that regression to the mean may explain our findings. However, our findings were not simply that impulse control improved over time, but that variance in such improvement was explained, in part, by grandiose-manipulative psychopathic traits.

Fourth, we employed a dichotomous operationalization of 'successful' (i.e., no reoffenses) and 'unsuccessful' (i.e., any re-offenses) individuals. To combat the limitation of having a dichotomous outcome, we attempted to approximate a continuous approach by varying the 'successful' categorization criteria (i.e., offended during fewer than three recall periods, offended during fewer than four, etc.). Our results replicated using these criteria such that, in each model, the 'successful' individuals showed stronger links between psychopathy and trajectories of self-regulatory variables (impulse control and suppression of aggression). Moreover, the difference in the strength of correlations between 'successful' and 'unsuccessful' individuals became smaller as the categorization criteria became more lenient (e.g., offended at four or more recall periods). Although this method is imperfect and cannot be used as a replacement for continuous approaches, our findings were robust suggesting that the trajectories of selfregulatory abilities for psychopathic individuals depends on their degree of 'success'. Still, 'success' in this context simply indicates engaging in fewer antisocial acts 
compared to individuals who have similar degrees of psychopathic tendencies. Future research should attempt to replicate these findings by applying a continuous definition and more objective metrics of the 'successful' construct, as this may alter the results.

Finally, the present study used only self-report measures, which are vulnerable to desirability bias, malingering, and deliberate inaccurate reporting - issues that may be heightened for individuals high in psychopathic traits. However, recent evidence suggests that, across college student and offender populations, response bias does not substantially differ between those high and low in psychopathic traits (Verschuere et al., 2014; Watts et al., 2016). Nonetheless, future studies should also include physiological data (e.g., skin conductance, neuroimaging), collateral reports (e.g., peers, family), maternal information (e.g., psychopathology, criminal record, substance abuse), and additional indicators of 'success' (e.g., relationship/marital stability) in order to provide a more comprehensive understanding of the relationships among psychopathy, conscientiousness, and antisocial behavior.

\section{Conclusions}

Overall, the findings from the present study provide support for the compensatory model of psychopathy and identify a psychological adaptation that 'successful' psychopathic individuals develop to overcome their antisocial proclivities conscientious impulse control. The conditions under which psychopathic traits become adaptive is another relatively nascent area of research that is in need of further exploration. The present study has taken essential steps towards these goals, which have implications for the development of more effective prevention and early 
intervention strategies. Studying and cultivating the strengths, not just the weaknesses, of psychopathic individuals is likely to be a productive path forward. 


\section{Acknowledgements}

Data used for this project were supported by the National Institute on Drug Abuse through a cooperative agreement that calls for scientific collaboration between the grantees and the National Institute on Drug Abuse staff. 


\section{References}

Andershed, H. A., Kerr, M., Stattin, H., \& Levander, S. (2002). Psychopathic traits in non-referred youths: A new assessment tool. In Psychopaths: Current international perspectives (pp. 131-158). Den Haag, Netherlands: Elsevier.

Benning, S. D., Venables, N. C., \& Hall, J. R. (2018). Successful psychopathy. In C. J. Patrick (Ed.), Handbook of psychopathy (p. 585-608). The Guilford Press.

Bronchain, J., Raynal, P., \& Chabrol, H. (2019). Heterogeneity of adaptive features among psychopathy variants. Personality Disorders: Theory, Research, and Treatment, 11(1), 63.

Cleckley, H. (1955). The mask of sanity: An attempt to clarify some issues about the socalled psychopathic personality. St Louis, MO, US: CV Mosby Co.

Clower, C. E., \& Bothwell, R. K. (2001). An exploratory study of the relationship between the Big Five and inmate recidivism. Journal of Research in Personality, 35(2), 231-237.

Gansler, D. A., Lee, A. K. W., Emerton, B. C., D’Amato, C., Bhadelia, R., Jerram, M., \& Fulwiler, C. (2011). Prefrontal regional correlates of self-control in male psychiatric patients: Impulsivity facets and aggression. Psychiatry Research: Neuroimaging, 191(1), 16-23.

Gao, Y., \& Raine, A. (2010). Successful and unsuccessful psychopaths: A neurobiological model. Behavioral Sciences \& the Law, 28(2), 194-210.

Gregory, S., Ffytche, D., Simmons, A., Kumari, V., Howard, M., Hodgins, S., \& Blackwood, N. (2012). The antisocial brain: Psychopathy matters: A structural 
MRI investigation of antisocial male violent offenders. Archives of General Psychiatry, 69(9), 962-972.

Hall, J. R., \& Benning, S. D. (2006). The "successful" psychopath. Handbook of psychopathy, 459-478.

Hare, R. D. (1999). Without conscience: The disturbing world of the psychopaths among us. New York, NY: Guilford Press.

Hare, R. D. (2003). The Hare psychopathy checklist-revised (2nd ed). Toronto, ON. Multi-Health Systems.

Huizinga, D., Esbensen, F. A., \& Weiher, A. W. (1991). Are there multiple paths to delinquency. Journal of Criminal Law \& Criminology, 82(1), 83-118.

Jonason, P. K., \& Tost, J. (2010). I just cannot control myself: The Dark Triad and selfcontrol. Personality and Individual Differences, 49(6), 611-615.

Jones, D. N., \& Figueredo, A. J. (2013). The core of darkness: Uncovering the heart of the Dark Triad. European Journal of Personality, 27(6), 521-531.

Kiehl, K., \& Lushing, J. (2014). Psychopathy. Scholarpedia, 9(5), 30835.

Konicar, L., Veit, R., Eisenbarth, H., Barth, B., Tonin, P., Strehl, U., \& Birbaumer, N. (2015). Brain self-regulation in criminal psychopaths. Scientific Reports, 5, 9426.

Lasko, E. N., Chester, D. S., Martelli, A. M., West, S. J., \& DeWall, C. N. (2019). An investigation of the relationship between psychopathy and greater gray matter density in lateral prefrontal cortex. Personality Neuroscience, 2.

Lilienfeld, S. O., Watts, A. L., \& Smith, S. F. (2015). Successful psychopathy: A scientific status report. Current Directions in Psychological Science, 24(4), 298303. 
Lilienfeld, S. O., Smith, S. F., Sauvigné, K. C., Patrick, C. J., Drislane, L. E., Latzman, R. D., \& Krueger, R. F. (2016). Is boldness relevant to psychopathic personality? Meta-analytic relations with non-Psychopathy Checklist-based measures of psychopathy. Psychological Assessment, 28(10), 1172.

Lykken, D. T. (1995). The antisocial personalities. London, UK: Psychology Press.

Lynam, D. R., \& Miller, J. D. (2015). Psychopathy from a basic trait perspective: The utility of a five-factor model approach. Journal of Personality, 83(6), 611-626.

Lynam, D. R., \& Widiger, T. A. (2007). Using a general model of personality to identify the basic elements of psychopathy. Journal of Personality Disorders, 21(2), 160178.

Marcus, D. K., Preszler, J., \& Zeigler-Hill, V. (2018). A network of dark personality traits: What lies at the heart of darkness?. Journal of Research in Personality, 73, 5662.

Miller, J. D., \& Lynam, D. R. (2003). Psychopathy and the five-factor model of personality: A replication and extension. Journal of Personality Assessment, 81(2), 168-178.

Mullins-Sweatt, S. N., Glover, N. G., Derefinko, K. J., Miller, J. D., \& Widiger, T. A. (2010). The search for the successful psychopath. Journal of Research in Personality, 44(4), 554-558.

Mulvey, E.P. (2017). Research on Pathways to Desistance [Maricopa County, AZ and Philadelphia County, PA]: Subject Measures, 2000-2010. Ann Arbor, MI: Interuniversity Consortium for Political and Social Research [distributor], 2016-03-14. 
Meyers, L. S., Gamst, G., \& Guarino, A. J. (2016). Applied multivariate research: Design and interpretation. Thousand Oaks, CA: Sage.

Nomura, M. (2011). The interplay of genetic and environmental influences on prefrontal function and self-regulation of impulsivity. Psychologia, 54(4), 241-251.

Ozer, D. J., \& Benet-Martinez, V. (2006). Personality and the prediction of consequential outcomes. Annual Review of Psychology, 57, 401-421.

Patrick, C. J., \& Drislane, L. E. (2015). Triarchic model of psychopathy: Origins, operationalizations, and observed linkages with personality and general psychopathology. Journal of Personality, 83(6), 627-643.

Patton, C., Smith, S. F., \& Lilienfeld, S. O. (2017). Psychopathy and heroism in first responders: Traits cut from the same cloth? Personality Disorders: Theory, Research, and Treatment. 9(4), 354-368.

Preacher, K. J., Wichman, A. L., Briggs, N. E., \& MacCallum, R. C. (2008). Latent growth curve modeling (No. 157). Thousand Oaks, CA: Sage.

Roberts, B. W., Bogg, T., Walton, K. E., Chernyshenko, O. S., \& Stark, S. E. (2004). A lexical investigation of the lower-order structure of conscientiousness. Journal of Research in Personality, 38(2), 164-178.

Roberts, B. W., Jackson, J. J., Fayard, J. V., Edmonds, G., \& Meints, J. (2009). Conscientiousness. In M. R. Leary \& R. H. Hoyle (Eds.), Handbook of individual differences in social behavior (p. 369-381). The Guilford Press.

Skeem, J. L., Poythress, N., Edens, J. F., Lilienfeld, S. O., \& Cale, E. M. (2003). Psychopathic personality or personalities? Exploring potential variants of 
psychopathy and their implications for risk assessment. Aggression and Violent Behavior, 8(5), 513-546.

Thomson, N. D. (2019). Understanding psychopathy: The biopsychosocial perspective. Routledge.

Verschuere, B., Uzieblo, K., De Schryver, M., Douma, H., Onraedt, T., \& Crombez, G. (2014). The inverse relation between psychopathy and faking good: Not response bias, but true variance in psychopathic personality. The Journal of Forensic Psychiatry \& Psychology, 25(6), 705-713.

Vize, C. E., Collison, K. L., Miller, J. D., \& Lynam, D. R. (2019). Using Bayesian methods to update and expand the meta-analytic evidence of the five-factor model's relation to antisocial behavior. Clinical Psychology Review, 67, 61-77.

Voelkle, M. C. (2007). Latent growth curve modeling as an integrative approach to the analysis of change. Psychology Science, 49(4), 375-414.

von Oertzen, T., \& Brandmaier, A. M. (2013). Optimal study design with identical power: An application of power equivalence to latent growth curve models. Psychology and Aging, 28(2), 414-428.

Watts, A. L., Lilienfeld, S. O., Edens, J. F., Douglas, K. S., Skeem, J. L., Verschuere, B., \& LoPilato, A. C. (2016). Does response distortion statistically affect the relations between self-report psychopathy measures and external criteria?. Psychological Assessment, 28(3), 294-306.

Weinberger, D. A., \& Schwartz, G. E. (1990). Distress and restraint as superordinate dimensions of self-reported adjustment: A typological perspective. Journal of Personality, 58(2), 381-417. 


\section{Supplemental Table 1}

Descriptive statistics for all 10 time points. GM = Grandiose-Manipulative psychopathy traits, IRR = Impulsive-Irresponsible psychopathy traits, IC = Impulse Control, NEO-C = NEO Conscientiousness, SA = Suppression of Aggression, $T O=$ Total Offense frequency count. Some range statistics are missing because the data sharing policy of the dataset used does not permit specific lower and upper bounds for these variables.

\begin{tabular}{ccccccc} 
& $N$ & $M$ & $S D$ & Range & Skewness & $\alpha$ \\
\hline Time 1 & (Females) & & & & & \\
Age & $1265(171)$ & 16.55 & 1.15 & - & - & - \\
GM & $1079(171)$ & 2.03 & 0.59 & $1.00-4.00$ & 0.36 & .91 \\
IRR & $1079(171)$ & 2.38 & 0.55 & $1.00-4.00$ & 0.01 & .82 \\
IC & $1261(171)$ & 3.01 & 0.94 & $1.00-5.00$ & 0.01 & .78 \\
SA & $1261(171)$ & 2.76 & 0.96 & $1.00-5.00$ & 0.20 & .79 \\
TO & $1261(171)$ & 13.44 & 71.00 & - & 13.20 & - \\
Time 2 & & & & & & - \\
Age & $1262(175)$ & 17.05 & 1.15 & - & - & - \\
GM & $1260(175)$ & 1.99 & 0.57 & $1.00-4.00$ & 0.53 & .91 \\
IRR & $1260(175)$ & 2.32 & 0.56 & $1.00-4.00$ & 0.17 & .83 \\
IC & $1260(175)$ & 3.16 & 0.96 & $1.00-5.00$ & -0.02 & .80 \\
SA & $1260(175)$ & 2.86 & 0.94 & $1.00-5.00$ & 0.17 & .78 \\
TO & $1260(175)$ & 10.59 & 47.14 & - & 13.03 & - \\
Time 3 & & & & & & - \\
Age & $1229(171)$ & 17.52 & 1.14 & - & - & .92 \\
GM & $1227(171)$ & 1.94 & 0.58 & $1.00-4.00$ & 0.41 & .95 \\
IRR & $1227(171)$ & 2.26 & 0.58 & $1.00-3.93$ & -0.01 & .85 \\
IC & $1228(171)$ & 3.16 & 0.97 & $1.00-5.00$ & -0.09 & .81 \\
SA & $1228(171)$ & 2.92 & 0.98 & $1.00-5.00$ & 0.15 & .82 \\
TO & $1228(171)$ & 12.54 & 61.07 & - & 12.98 & - \\
Time 4 & & & & & & \\
Age & $1231(170)$ & 18.02 & 1.14 & - & - & - \\
GM & $1225(170)$ & 1.97 & 0.58 & $1.00-3.95$ & 0.36 & .92 \\
IRR & $1225(170)$ & 2.30 & 0.55 & $1.00-4.00$ & -0.06 & .84 \\
IC & $1229(170)$ & 3.04 & 0.95 & $1.00-5.00$ & 0.14 & .80 \\
SA & $1229(170)$ & 2.83 & 0.95 & $1.00-5.00$ & 0.22 & .81 \\
TO & $1230(170)$ & 13.16 & 69.51 & - & 11.17 & - \\
Time 5 & & & & & & - \\
Age & $1234(173)$ & 18.49 & 1.15 & - & - & -
\end{tabular}




\begin{tabular}{|c|c|c|c|c|c|c|}
\hline GM & 1230 (173) & 1.92 & 0.56 & $1.00-3.85$ & 0.38 & .91 \\
\hline IRR & $1230(173)$ & 2.23 & 0.56 & $1.00-3.87$ & 0.01 & .84 \\
\hline IC & 1233 (173) & 3.15 & 0.95 & $1.00-5.00$ & 0.06 & .76 \\
\hline SA & $1233(173)$ & 2.92 & 0.98 & $1.00-5.00$ & 0.18 & .82 \\
\hline TO & 1233 (173) & 18.79 & 122.16 & - & 12.51 & - \\
\hline \multicolumn{7}{|l|}{ Time 6} \\
\hline Age & 1232 (176) & 19.01 & 1.15 & - & - & - \\
\hline GM & $1230(176)$ & 1.91 & 0.56 & $1.00-4.00$ & 0.44 & .91 \\
\hline IRR & $1230(176)$ & 2.23 & 0.57 & $1.00-4.00$ & 0.12 & .84 \\
\hline IC & 1232 (176) & 3.19 & 0.97 & $1.00-5.00$ & -0.02 & .78 \\
\hline SA & 1232 (176) & 2.96 & 0.96 & $1.00-5.00$ & 0.18 & .81 \\
\hline TO & $1231(176)$ & 15.41 & 85.20 & - & 9.33 & - \\
\hline \multicolumn{7}{|l|}{ Time 7} \\
\hline Age & 785 (173) & 20.03 & 1.15 & - & - & - \\
\hline GM & 1215 (173) & 1.87 & 0.54 & $1.00-4.00$ & 0.55 & .91 \\
\hline IRR & $1211(173)$ & 2.21 & 0.58 & $1.00-4.00$ & 0.07 & .85 \\
\hline IC & 1213 (173) & 3.22 & 0.96 & $1.00-5.00$ & -0.10 & .76 \\
\hline SA & 1213 (173) & 3.23 & 0.93 & $1.00-5.00$ & 0.05 & .79 \\
\hline TO & 1209 (173) & 24.71 & 95.53 & - & 6.69 & - \\
\hline \multicolumn{7}{|l|}{ Time 8} \\
\hline Age & 1207 (176) & 21.02 & 1.15 & - & - & - \\
\hline GM & 1203 (176) & 1.83 & 0.55 & $1.00-3.85$ & 0.53 & .92 \\
\hline IRR & 1203 (176) & 2.16 & 0.59 & $1.00-4.00$ & 0.18 & .86 \\
\hline IC & $1204(176)$ & 3.22 & 0.98 & $1.00-5.00$ & -0.13 & .78 \\
\hline SA & $1204(176)$ & 3.07 & 0.96 & $1.00-5.00$ & 0.06 & .81 \\
\hline TO & $1201(176)$ & 22.74 & 93.69 & - & 7.13 & - \\
\hline \multicolumn{7}{|l|}{ Time 9} \\
\hline Age & 1179 (175) & 22.03 & 1.15 & - & - & - \\
\hline GM & $1176(175)$ & 1.78 & 0.53 & $1.00-3.65$ & 0.58 & .91 \\
\hline IRR & $1176(175)$ & 2.16 & 0.58 & $1.00-4.00$ & 0.19 & .86 \\
\hline IC & 1179 (175) & 3.29 & 0.98 & $1.00-5.00$ & -0.11 & .80 \\
\hline SA & 1179 (175) & 3.14 & 0.97 & $1.00-5.00$ & 0.10 & .82 \\
\hline TO & 1169 (175) & 22.57 & 126.64 & - & 15.68 & - \\
\hline \multicolumn{7}{|l|}{ Time 10} \\
\hline Age & $1134(172)$ & 23.03 & 1.15 & - & - & - \\
\hline GM & $1131(172)$ & 1.78 & 0.53 & $1.00-3.65$ & 0.52 & .92 \\
\hline IRR & 1131 (172) & 2.15 & 0.56 & $1.00-4.00$ & 0.19 & .87 \\
\hline IC & 1131 (172) & 3.29 & 0.97 & $1.00-5.00$ & -0.20 & .80 \\
\hline SA & $1131(172)$ & 3.14 & 0.97 & $1.00-5.00$ & 0.03 & .84 \\
\hline $\mathrm{TO}$ & $1126(172)$ & 15.16 & 71.32 & - & 9.35 & - \\
\hline
\end{tabular}




\section{Supplemental Table 2}

Bivariate correlations among all variables and between recall periods 4 and 10 .

\begin{tabular}{|c|c|c|c|c|c|c|c|c|c|c|c|c|c|}
\hline & 1 & 2 & 3 & 4 & 5 & 6 & 7 & 8 & 9 & 10 & 11 & 12 & 13 \\
\hline $\begin{array}{l}\text { 1. YPI: Grandiose- } \\
\text { Manipulative T4 }\end{array}$ & - & - & - & - & - & - & - & - & - & - & - & - & - \\
\hline $\begin{array}{l}\text { 2. YPI: Callous- } \\
\text { Unemotional T4 }\end{array}$ & $.65^{\star *}$ & - & - & - & - & - & - & - & - & - & - & - & - \\
\hline $\begin{array}{l}\text { 3. YPI: Impulsive- } \\
\text { Irresponsible T4 }\end{array}$ & $.67^{\star \star}$ & $.59^{\star *}$ & - & - & - & - & - & - & - & - & - & - & - \\
\hline 4. NEO-C T4 & $-.21^{\star \star}$ & $-.28^{\star *}$ & $-.38^{\star \star}$ & - & - & - & - & - & - & - & - & - & - \\
\hline $\begin{array}{l}\text { 5. SRO: Offending } \\
\text { T4 }\end{array}$ & $.13^{\star \star}$ & $.13^{\star \star}$ & $.15^{\star \star}$ & $-.07^{\star *}$ & - & - & - & - & - & - & - & - & - \\
\hline $\begin{array}{l}\text { 6. WAI: } \\
\text { Suppression of } \\
\text { Aggression T4 }\end{array}$ & $-.42^{\star \star}$ & $-.44^{\star *}$ & $-.49^{\star *}$ & $.25^{\star \star}$ & $-.13^{\star *}$ & - & - & - & - & - & - & - & - \\
\hline $\begin{array}{l}\text { 7. WAI: Impulse } \\
\text { Control T4 }\end{array}$ & $-.38^{\star \star}$ & $-.33^{\star *}$ & $-.42^{\star \star}$ & $.38^{* *}$ & $-.07^{\star *}$ & $.32^{\star \star}$ & - & - & - & - & - & - & - \\
\hline $\begin{array}{l}\text { 8. YPI: Grandiose- } \\
\text { Manipulative T10 }\end{array}$ & $.50^{\star \star}$ & $.32^{\star \star}$ & $.35^{\star \star}$ & $-.10^{\star \star}$ & .06 & $-.24^{\star *}$ & $-.25^{\star *}$ & - & - & - & - & - & - \\
\hline $\begin{array}{l}\text { 9. YPI: Callous- } \\
\text { Unemotional T10 }\end{array}$ & $.37^{\star *}$ & $.47^{\star \star}$ & $.29^{\star *}$ & $-.14^{\star *}$ & $.09^{* *}$ & $-.27^{\star \star}$ & $-.24^{* *}$ & $.63^{\star *}$ & - & - & - & - & - \\
\hline $\begin{array}{l}\text { 10. YPI: Impulsive- } \\
\text { Irresponsible T10 }\end{array}$ & $.40^{\star *}$ & $.31^{\star \star}$ & $.49^{* *}$ & $-.26^{\star \star}$ & $.07^{*}$ & $-.27^{\star \star}$ & $-.38^{\star *}$ & $.65^{\star *}$ & $.53^{* *}$ & - & - & - & - \\
\hline $\begin{array}{l}\text { 11. SRO: } \\
\text { Offending T10 }\end{array}$ & $.10^{* *}$ & $.16^{\star \star}$ & $.07^{*}$ & -.04 & $.10^{\star *}$ & $-.15^{\star \star}$ & -.05 & $.13^{\star \star}$ & $.17^{\star \star}$ & $.10^{\star *}$ & - & - & - \\
\hline $\begin{array}{l}\text { 12. WAI: } \\
\text { Suppression of } \\
\text { Aggression T10 }\end{array}$ & $-.33^{* *}$ & $-.32^{\star *}$ & $-.32^{\star \star}$ & $.15^{\star \star}$ & $-.12^{\star *}$ & $.49^{* *}$ & $.29^{\star *}$ & $-.45^{\star \star}$ & $-.45^{\star \star}$ & $-.46^{\star *}$ & $-.18^{\star \star}$ & - & - \\
\hline $\begin{array}{l}\text { 13. WAI: Impulse } \\
\text { Control T10 }\end{array}$ & $-.33^{\star *}$ & $-.29^{\star \star}$ & $-.42^{\star *}$ & $.30^{\star *}$ & -.06 & $.32^{\star \star}$ & $.52^{\star \star}$ & $-.43^{\star \star}$ & $-.39^{\star *}$ & $-.64^{\star *}$ & $-.15^{\star \star}$ & $.55^{\star}$ & - \\
\hline
\end{tabular}

Note. $\mathrm{YPI}=$ Youth Psychopathic Traits Inventory, $W A I=$ Weinberger Adjustment Inventory, $S R O=$ Self-Report Offending Questionnaire, $T 4=$ recall period $4, T 10=$ recall period $10 .{ }^{* *} p<.001,{ }^{*} p<.01$ 


\section{Supplemental Table 3}

Associations between the intercept of Grandiose-Manipulative psychopathy traits and the slope of Impulse Control, separately for 'Successful' and 'Unsuccessful' participants. Rows represent different cutoffs used for the number of recall periods during which participants had to commit criminal re-offenses to be considered 'Unsuccessful'.

\begin{tabular}{lcccccc}
\hline Re-Offense & \multicolumn{3}{c}{ 'Successful' } & \multicolumn{2}{c}{ 'Unsuccessful' } \\
\cline { 2 - 7 } Cutoff & $N$ & $\beta$ & $p$ & $N$ & $\beta$ & $p$ \\
\hline 2 & 171 & .57 & .012 & 672 & .32 & $<.001$ \\
3 & 273 & .52 & $<.001$ & 570 & .32 & $<.001$ \\
4 & 364 & .49 & $<.001$ & 479 & .30 & $<.001$ \\
\hline
\end{tabular}

Note. Using a cutoff of 1 resulted in too few 'successful' people to provide reliable estimates, therefore this cutoff was not used. 


\section{Supplemental Table 4}

Associations between the intercept of Grandiose-Manipulative psychopathy traits and the slope of Impulse Control, separately for 'Successful' and 'Unsuccessful' participants. Rows represent different cutoffs used for the minimum number of time points participants had to be enrolled in school to be considered 'Unsuccessful'.

\begin{tabular}{lcccccc}
\hline \multirow{2}{*}{$\begin{array}{l}\text { School Enrollment } \\
\text { Cutoff }\end{array}$} & \multicolumn{3}{c}{ 'Successful' } & \multicolumn{5}{c}{ 'Unsuccessful' } \\
\cline { 2 - 7 } & $N$ & $\beta$ & $p$ & $N$ & $\beta$ & $p$ \\
\hline 8 & 127 & .91 & .044 & 1210 & .35 & $<.001$ \\
7 & 268 & .48 & .008 & 1069 & .35 & $<.001$ \\
6 & 434 & .45 & $<.001$ & 903 & .33 & $<.001$ \\
5 & 630 & .42 & $<.001$ & 707 & .32 & $<.001$ \\
\hline
\end{tabular}




\section{Supplemental Table 5}

Associations between the intercept of Grandiose-Manipulative psychopathy traits and the slope of Suppression of Aggression, separately for 'Successful' and 'Unsuccessful' participants. Rows represent different cutoffs used for the number of recall periods during which participants had to commit criminal re-offenses to be considered 'Unsuccessful'.

\begin{tabular}{lcccccc}
\hline Re-Offense & \multicolumn{4}{c}{ 'Successful' } & \multicolumn{2}{c}{ 'Unsuccessful' } \\
\cline { 2 - 7 } Cutoff & $N$ & $\beta$ & $p$ & $N$ & $\beta$ & $p$ \\
\hline 2 & 171 & .46 & .012 & 672 & .39 & $<.001$ \\
3 & 273 & .63 & $<.001$ & 570 & .35 & $<.001$ \\
4 & 364 & .57 & $<.001$ & 479 & .35 & $<.001$
\end{tabular}

Note. Using a cutoff of 1 resulted in too few 'successful' people to provide reliable estimates, therefore this cutoff was not used. 
Supplemental Table 6

Associations between the intercept of Grandiose-Manipulative psychopathy traits and the slope of Suppression of Aggression, separately for 'Successful' and 'Unsuccessful' participants. Rows represent different cutoffs used for the minimum number of time points participants had to be enrolled in school to be considered 'Unsuccessful'.

\begin{tabular}{lcccccc}
\hline \multirow{2}{*}{$\begin{array}{l}\text { School } \\
\text { Enrollment Cutoff }\end{array}$} & $N$ & $\beta$ & $p$ & $N$ & $\beta$ & $p$ \\
\hline 8 & 127 & .98 & .043 & 1210 & .39 & $<.001$ \\
7 & 268 & .63 & $<.001$ & 1069 & .37 & $<.001$ \\
6 & 434 & .63 & $<.001$ & 903 & .32 & $<.001$ \\
5 & 630 & .54 & $<.001$ & 707 & .29 & $<.001$ \\
\hline
\end{tabular}


Supplemental Table 7

Latent growth trajectories of Impulsive-Irresponsible (IRR) traits and Impulse Control (IC) for 'Successful' and 'Unsuccessful' participants.

\begin{tabular}{|c|c|c|c|c|}
\hline \multirow[b]{2}{*}{ Path } & \multicolumn{2}{|c|}{ 'Successful' $(N=230)$} & \multicolumn{2}{|c|}{ 'Unsuccessful' $(N=1030)$} \\
\hline & $\bar{\beta}$ & $p$ & $\beta$ & $p$ \\
\hline $\operatorname{IRR}(\mathrm{I})<-->\operatorname{IRR}(\mathrm{S})$ & 0.63 & $<.001$ & 0.68 & $<.001$ \\
\hline IC $(\mathrm{I})<-->$ IC $(\mathrm{S})$ & 0.77 & $<.001$ & 0.69 & $<.001$ \\
\hline $\operatorname{IRR}(\mathrm{S})<-->\operatorname{IC}(\mathrm{I})$ & -0.39 & $<.001$ & -0.29 & $<.001$ \\
\hline $\operatorname{IRR}(S)<-->\operatorname{IC}(S)$ & -1.05 & $<.001$ & -1.36 & $<.001$ \\
\hline $\operatorname{IRR}(\mathrm{I})<-->\operatorname{IC}(\mathrm{S})$ & -0.38 & .001 & -0.24 & $<.001$ \\
\hline $\operatorname{IRR}(\mathrm{I})<-->\operatorname{IC}(\mathrm{I})$ & -1.00 & $<.001$ & -1.04 & $<.001$ \\
\hline
\end{tabular}


Supplemental Table 8

Latent growth trajectories of Impulsive-Irresponsible (IRR) traits and suppression of aggression (SUP) for 'Successful' and 'Unsuccessful' participants.

\begin{tabular}{ccccc}
\hline & \multicolumn{2}{c}{ 'Successful' $(N=230)$} & 'Unsuccessful' $(N=1030)$ \\
\cline { 2 - 5 } Path & $\beta$ & $p$ & $\beta$ & $p$ \\
\hline IRR $($ I) $<-->$ IRR (S) & 0.71 & $<.001$ & 0.71 & $<.001$ \\
SUP (I) <--> SUP (S) & 0.69 & $<.001$ & 0.50 & $<.001$ \\
IRR (S) <--> SUP (I) & -0.26 & .036 & -0.08 & .172 \\
IRR (S) <--> SUP (S) & -0.98 & $<.001$ & -0.91 & $<.001$ \\
IRR (I) <--> SUP (S) & -0.06 & .643 & -0.15 & .010 \\
IRR (I) $<-->$ SUP (I) & -1.05 & $<.001$ & -0.87 & $<.001$ \\
\hline
\end{tabular}

